\title{
Patient education booklet to support evidence-based low back pain care in primary care - a cluster randomized controlled trial
}

Anna S. Simula ${ }^{1,2^{*}}$, Hazel J. Jenkins ${ }^{3,4}$, Mark J. Hancock ${ }^{3}$, Antti Malmivaara ${ }^{5}$, Neill Booth ${ }^{6}$ and Jaro Karppinen ${ }^{1,7,8}$

\begin{abstract}
Background: Inappropriate imaging and low-value care for low back pain (LBP) are common. A new patient-education booklet was created to overcome identified barriers to the delivery of recommended care, including the use of inappropriate imaging. Our aim was to assess the effectiveness of this booklet as part of primary care for LBP patients in comparison to usual care.

Methods: A cluster-randomized trial was performed. The intervention involved providing practitioners with the new patient-education booklet and a 30-min training session on its use. The booklet was provided during the clinical consult to all consenting LBP patients in the intervention group. Primary outcomes were the proportion of patients presenting with LBP who underwent imaging examinations during the first three months of follow-up and PROMIS PF-20 (Patient-Reported Outcomes Measurement Information System, 20-item physical functioning short form) change between baseline and three-month follow-up. Secondary outcomes, including sick leave and imaging examinations at 12 months, were investigated. Logistic regression using GEE-estimation was used for dichotomous outcomes, Poisson regression using GEE-estimation for count outcomes, and linear mixed models for continuous outcomes.

Results: Using the patient education booklet appeared to substantially reduce the proportion of LBP patients who underwent an imaging examination at three months, but the result was not statistically significant (OR $0.57,95 \%$ confidence interval (Cl) 0.27 to 1.22). At 12 months, the effect was slightly larger and statistically significant (OR 0.50 , $95 \% \mathrm{Cl} 0.30$ to $0.83, p=0.008$ ). No difference was observed in the PROMIS PF-20 T-score change between baseline and 3 months or 12 months ( $p=0.365$ and $p=0.923$, respectively). The number of sick leave days in the intervention group was less than that in the control group at 3 months (RR $0.47,95 \% \mathrm{Cl} 0.26$ to $0.83, p=0.010$ ) and at 12 months (RR $0.36,95 \% \mathrm{Cl} 0.18$ to $0.72, \mathrm{p}=0.004$ ).
\end{abstract}

Conclusions: The booklet appeared to be effective in reducing the proportion of LBP patients who underwent imaging examinations over 12 months. The intervention had no discernible effect on the PROMIS PF20 T-score change. The number of sick leave days was substantially lower in the intervention group.

Trial registration: ISRCTN, ISRCTN14389368, Registered 4 April 2019-Retrospectively registered.

Keywords: Low back pain, Primary care, Cluster randomized study, Guideline implementation, Patient education, Low back pain imaging

*Correspondence: anna.simula@oulu.fi

${ }^{1}$ Medical Research Center Oulu, Oulu University Hospital and University

of Oulu, P.O. Box 8000, 90014 Oulu, Finland

Full list of author information is available at the end of the article original author(s) and the source, provide a link to the Creative Commons licence, and indicate if changes were made. The images or other third party material in this article are included in the article's Creative Commons licence, unless indicated otherwise in a credit line to the material. If material is not included in the article's Creative Commons licence and your intended use is not permitted by statutory regulation or exceeds the permitted use, you will need to obtain permission directly from the copyright holder. To view a copy of this licence, visit http://creativecommons.org/licenses/by/4.0/. The Creative Commons Public Domain Dedication waiver (http://creativeco mmons.org/publicdomain/zero/1.0/) applies to the data made available in this article, unless otherwise stated in a credit line to the data. 


\section{Background}

Low back pain (LBP) has been estimated as the leading cause of global years lived with disability in many countries and is one of the most costly health problems worldwide [1-3]. Management of LBP is often inconsistent with guidelines, and low-value care, such as inappropriate imaging, is common $[4,5]$. For example, one third to one half of LBP patients undergo inappropriate imaging [6], which has been associated with increased health care costs, increased downstream health care utilization and increased disability [7-10]. Increased compliance with guidelines has shown to reduce health care costs and worker's compensation claims [11].

The implementation of clinical guidelines for LBP is complicated and has several physician- and patientreported barriers [12, 13]. Australian researchers have developed a new patient education booklet which focuses on both physician- and patient-related barriers and: 1) provides patient and practitioner education; 2) reminds practitioners of recommended care; 3 ) provides clinical decision support; and 4) facilitates practitioner-patient communication [14]. The booklet has been translated into and validated in Finnish. Preliminary evaluation by patients and practitioners in Finland has suggested that the booklet may be helpful in LBP management and in decreasing the need for LBP imaging [15].

\section{Trial objectives}

The primary objective of this cluster randomized controlled trial was to assess the effectiveness of the "Understanding low back pain" patient-education booklet in addition to usual care in comparison to usual care alone, in reducing the proportion of patients presenting with LBP who undergo imaging examinations due to LBP over the first three months of follow-up (individual participant-level data), and to improve physical functioning at three-month follow-up (individual participant-level data).

The secondary objective was to assess the effectiveness of the intervention in reducing the proportion of patients presenting with LBP who undergo imaging examinations due to LBP, LBP-related sick leave days, health care appointments and disability, and to improve physical functioning and quality of life over 3-and 12-month follow-ups (individual participant-level data).

\section{Methods}

We used a cluster-randomized trial design to assess the effectiveness of using the patient education booklet with LBP patients in primary care in comparison to usual care. Ethics approval was granted by the Ethics Committee of the University Hospital of Oulu. The study was reported in accordance with the CONSORT 2010 checklist with extension for Cluster Trials. The trial was retrospectively registered at ISRCTN (ISRCTN14389368, Registered 4 April 2019).

\section{Trial design and participants}

Figure 1 presents a flow chart of the trial design and participants. We used cluster randomization to minimize contamination between the intervention and control groups. Cluster randomization was performed at the health care region level rather than at the practitioner level, because patients would be evaluated by different health care professionals in the same health care region. We selected six public health care regions and two occupational health service organizations for clusters. The clusters were chosen and matched according to population size and type of health care provider (public or occupational) (Fig. 1). The managers of all the participating centres in the clusters were informed of the study and consented to participate before pairwise randomization into control or intervention groups was performed by an external statistician using a random number generator. Blinding was impossible because of the study design [16]. All the physicians and physiotherapists in the study clusters were invited to participate in the study and recruit eligible patients for the study.

In all the centres (in both the intervention and control groups), we provided the professionals (physiotherapists, nurses and physicians) with a 30-min training session, which covered the eligibility criteria and the overall study procedures (see Powerpoint slide show, Additional file 1). The physicians, physiotherapists and nurses identified eligible patients when they attended appointments for LBP. Selection bias was reduced by involving large numbers of professionals in the recruitment procedure. The professional explained the study to the patient and requested their consent. The professionals then sent the signed patient-consent forms to the research assistant (outside the centre). Whether a patient initially presented to a physiotherapist, physician or nurse did not change because of the study process. In Finland, LBP patients may initially present to a: 1) physician; 2) physiotherapist; 3) nurse together with a physician; or 4) nurse alone (the first contacted professional), depending on local care policies, the education level of the professionals, the availability of appointments at the time, and the patient's symptoms (usually determined by the triage nurse over the phone). The first professional each patient contacted and patient baseline information was identified from electronic patient record data. The research assistant repeatedly sent information and a reminder about the study to the physicians, physiotherapists and nurses every month. The email contained a patient information 


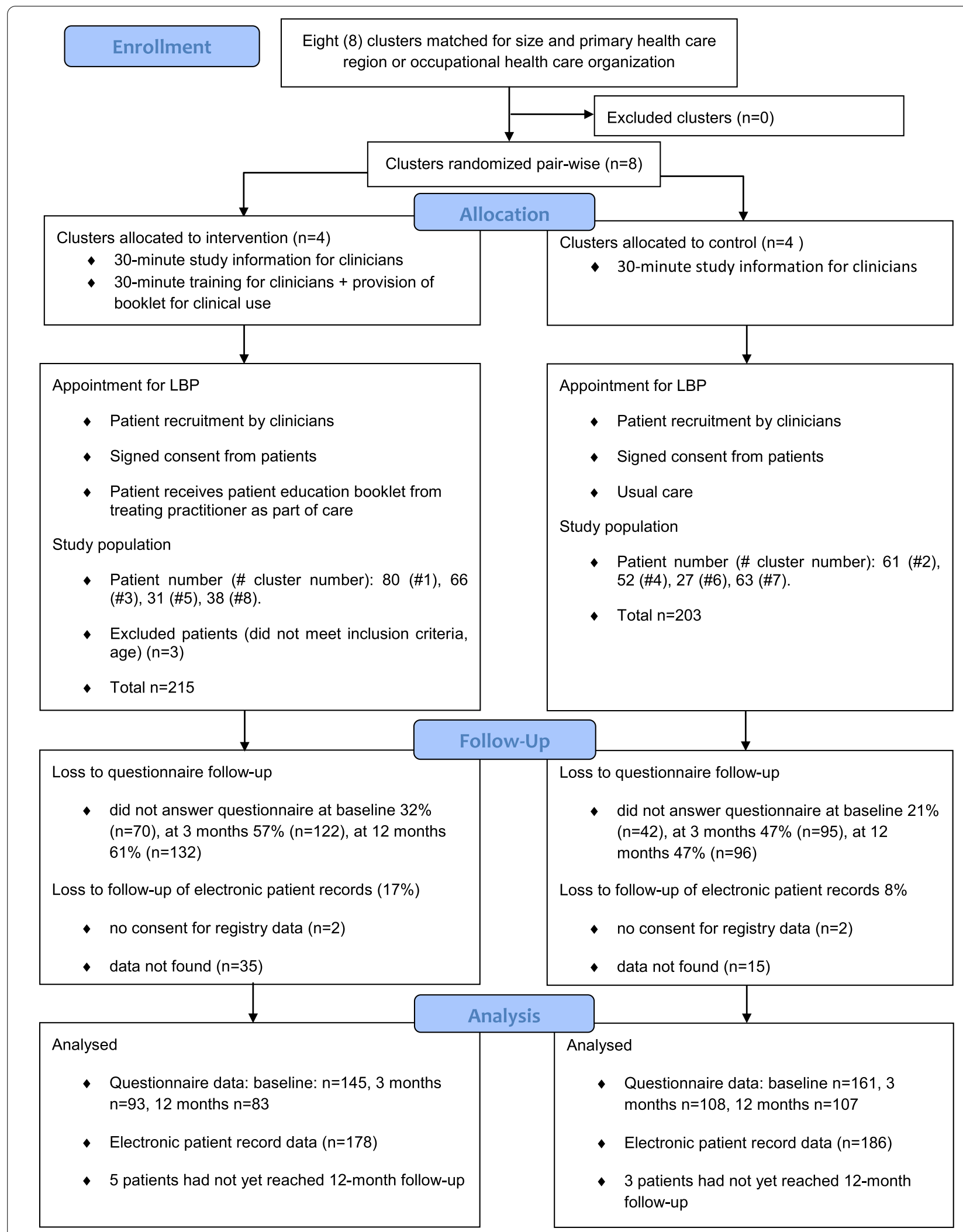

Fig. 1 Flow chart 
sheet, brief information on patient recruitment, and details on eligibility criteria. We asked them, to recruit consecutive patients.

The patients who were eligible for inclusion were aged 18 to 65 and presented for treatment for LBP with or without associated radicular pain, that had lasted for two weeks or less (low risk of prolonged pain) for the first time. The exclusion criteria included a suspected serious cause of LBP (for example, cancer, fracture or infection); or LBP requiring urgent (emergency) care, such as cauda equina syndrome. Only patients who signed a consent form were included as participants in the study and patients were free to discontinue their participation in the study at any time without a reason.

\section{Intervention}

The main focus of the intervention was the use of the patient education booklet in addition to usual care as part of the appointment with the professional (individual patient-level intervention). The professionals (physicians, physiotherapists and nurses) in the intervention arm attended a 30-min group training session on the booklet's content and how it should be used during appointments (see Powerpoint slide show, Additional file 2) (cluster-level intervention). The training sessions were held during the weekly clinic meetings to enhance participation. Smaller units could alternatively participate online. After the education session, the professionals were encouraged to use the booklet (printed Finnish version) in the manner that they preferred (e.g., to guide the whole interaction with the patient, or to emphasize key points at the end of the consultation, etc.) during the LBP patients' appointments. In the trial, patients were considered to have received the intervention if the health professional provided the booklet to the patient during or after the consultation, with or without further discussion. This was done in order to avoid potential limitations to the delivery of the intervention caused by health care professionals' time limits or patients' receptivity to education. Health care professionals were asked to recruit consecutive patients; however, records were not kept concerning whether or not consecutive patients who met the inclusion criteria were recruited by the health-care professionals. The English version of the booklet is available online (https:// tinyurl.com/lowbackpaineducation). Other aspects of care were provided as usual. All the consenting LBP patients in the intervention health care units received the booklet from their physician, physiotherapist or nurse.

\section{Control}

The professionals in the control arm received a short training session on the study and recruitment procedure only. All the consenting LBP patients presenting to the control clinics received usual care without the booklet.

\section{Outcomes}

The two primary outcomes were as follows: 1 ) The proportion of patients presenting with LBP who underwent imaging examinations due to LBP during the first three months of follow-up; and 2) Change in PROMIS PF-20 T-score (Patient-Reported Outcomes Measurement Information System, 20-item physical functioning short form) from baseline to three-month follow-up (individual patient level) $[17,18]$. Imaging data were collected from electronic patient record data to determine the proportion of patients presenting with LBP who had undergone imaging examinations due to LBP (yes/no). The patient-reported outcomes were collected using web-based questionnaires.

The secondary outcomes were determined from the electronic patient record data on the basis of the following: the proportion of patients presenting with LBP who had undergone imaging examinations due to LBP over 12 months of follow-up; imaging examinations stratified by the type of imaging [radiographs/ magnetic resonance imaging (MRI)/computer tomography $(\mathrm{CT})$ ] over 3- and 12-month follow-ups; the number of LBP-related sick leave days; and the number of LBP-related health care professional appointments (primary care: physician, physiotherapist, nurse; secondary health: physiatrist and orthopaedist) during the 3- and 12-month follow-up.

The secondary patient reported outcomes were: change in Oswestry Disability Index (ODI) between baseline and 12-month follow-up [19]; change in Roland Morris disability questionnaire between baseline and 12-month follow-up; change in PROMIS (Patient-Reported Outcomes Measurement Information System) (short form 20a) between baseline and 12-month follow-up; change in LBP intensity (0-10 Numerical Rating Scale (NRS)) during past week between baseline and 3-and 12-month follow-ups; change in leg pain intensity (0-10 NRS) during past week between baseline and 3- and 12-month follow-ups; and change in EQ-5D (EuroQol five dimensions) between baseline and 12-month follow-ups [20] and Frequency of LBP during last three months at baseline, 3- and 12-month follow-ups (daily LBP yes/no).

\section{Electronic patient record data}

In each health care region or organization of the study, all the primary health care professionals (physicians, physiotherapist, nurses, etc.) use the same electronic 
patient record data. The data are organized according to professions (e.g., one file for primary health care physicians, another file for physiotherapists, etc.). Imaging examinations are documented on separate files and contain lists of completed examinations and imaging reports. All health care professionals have access to both primary and secondary electronic health care data directly or through passcode-protected access to the nationwide database. The input of health data is obligatory for health care providers. Nationwide electronic patient record data are accessible to all health care providers in Finland. The data were collected manually from the organizational database by the first author or one of two research assistants, using a paper checklist for each patient (Additional file 3). Initially, to ensure congruency, the checklist data for 10 patients were extracted independently by two people and compared. The original data collection sheets of each patient have been retained to allow subsequent data checks if required. Electronic patient record data were collected from the date of informed signed consent up to the 3- and 12- month follow-ups.

\section{Patient questionnaire data}

Patient-reported data were collected using online questionnaires sent to the patients via an email hyperlink. The baseline questionnaire was collected after the patient consented to participate and after the first appointment; the follow-up questionnaire was collected 3 months and 12 months after the baseline questionnaire. If the patients did not complete the baseline and follow-up questionnaires within one week, the research assistant resent the hyperlink via email. If an email address was missing, the research assistant sent a paper version of the questionnaire. Further reminders were sent at two weeks and three weeks to the patients who had not responded to the baseline, 3-month or 12-month questionnaires by a text message containing a hyperlink to the related questionnaire.

\section{Changes to the protocol}

Changes were made to the original protocol because of unreliable data relating to one of the original secondary outcome measures (pain medication) and in order to respect the original purpose of the STarT Back Tool (SBT). We did not include the secondary outcome of pain medication as we could not accurately extract these data from the electronic records, and we only used SBT to describe baseline differences, not as a secondary outcome measure.

\section{Sample size}

At baseline, the imaging rate (radiographs, MRI or CT) was expected to be $30 \%$. We used a web-based calculator to compare the proportion with a dichotomous outcome (imaging/nor imaging) of the two samples (http://www. sample-size.net/sample-size-proportions/). We estimated the Design Effect (DE) for unequal clusters in a clusterrandomized design to increase the statistical power of the cluster randomized study: DEunequal $=1+\left[\left(1+C V^{2}\right)\right.$ $\mathrm{x} \mathrm{m} \mathrm{-1]} \rho$; when $\rho(\mathrm{ICC})=0.01$; coefficient of variation of cluster size $(\mathrm{CV})$ was $0.208 ; \mathrm{CV}=\mathrm{sd} / \mathrm{m},(\mathrm{sd}=$ standard deviation of mean cluster size; $\mathrm{m}=$ mean cluster size); $\mathrm{sd}=\mathrm{CSrange} / 4(\mathrm{CS}=$ cluster size $)$ [21]. A sample size of 408 patients would enable the detection of an absolute $15 \%$ decrease in imaging proportion with $80 \%$ power and a type I error of 0.05 .

The sample of 408 could provide more than adequate power for the other primary outcome of PROMIS based on the sample size a web-based calculator for Inference for Means in clustered samples (http://www.sample-size. net/means-sample-sizeclustered/). The Minimal Important Difference (MID) for change in PROMIS PF-20 was about two points, and standard deviation (SD) was 3.66 [22]. The type I error rate was 0.05 , and the Intracluster Correlation Coefficient (ICC) 0.025 [23]. A sample size of 128 patients would enable the detection of a difference of two points in PROMIS PF-20 with $80 \%$ power.

\section{Statistical methods}

We analysed the between-group differences at baseline using independent-samples t-tests for normally distributed continuous variables, the Mann-Whitney U-tests for non-normally distributed continuous variables, and the Chi-square test or Fisher's exact tests for dichotomous variables.

The statistical methods used to analyse the differences between the intervention and control groups were selected according to the type of the outcome. We used logistic regression for dichotomous outcomes (imaging and LBP frequency), providing an estimated difference between the groups expressed as odds ratio (OR) with a $95 \%$ confidence interval (CI). Poisson regression was used for count outcomes (health care professional appointments and sick leave days), providing an estimated difference between the groups expressed as risk ratio (RR) with a 95\% confidence interval. Logistic and Poisson models were analysed using generalized estimating equations (GEE) with an exchangeable working correlation to account for the clustered nature of the data. We analysed the continuous outcomes (PROMIS, ODI, NRS for pain, EQ-5D index and EQ VAS) using a linear mixed model with random effects for clusters, providing an estimated least squares mean difference with a $95 \%$ confidence interval. Age-adjusted analyses were also conducted for all outcomes because of baseline differences.

Post-hoc sensitivity analyses were conducted for the primary outcomes based on the first contacted 
professional, as this was unbalanced between the groups and there was strong rationale for why the intervention may be more or less effective depending on the profession of the first professional contacted. In the Finnish health care system, physiotherapists cannot directly refer patients for imaging, so which professional the patient first contacted was particularly important for our imaging outcome. Statistical analyses were conducted using IBM SPSS Statistics for Windows, version 26 (IBM Corp., Armonk, NY). Two-sided tests were used, and p-values less than 0.05 were considered statistically significant.

\section{Results}

\section{Baseline characteristics}

The number of professionals who attended the training and study information sessions and participated in recruiting the intervention group were: Cluster 1: 18 of the 25 physicians, all 8 physiotherapists and 16 nurses; Cluster 3: 20 of the 31 physicians and 8 of the 16 physiotherapists; Cluster 5: 14 of the 19 physicians and 5 of the 8 physiotherapists; cluster $8: 7$ of the 10 physicians and 1 of the 5 physiotherapists.

The number of professionals who attended the study information sessions and participated in recruiting the control group were: Cluster 2: all 46 physicians and 12 of the 14 physiotherapists, 37 nurses; Cluster 4: 17 of the 27 physicians and 5 of the 12 physiotherapists; Cluster 6: 7 of the 25 physicians and 5 of the 6 physiotherapists; Cluster 7: 13 of the 18 physicians and 7 of the 13 physiotherapists.

In total, 418 LBP patients consented to participate in the study. Recruitment was carried out between $13^{\text {th }}$ April 2017 and $30^{\text {th }}$ May 2020. The number of participants in each cluster, the missing data in the follow-up questionnaires, and the missing data in the electronic patient records data are shown in Fig. 1. The patients in the intervention and control groups had similar characteristics at baseline (Tables 1 and 2). Approximately half of the patients were actively working. The patients' mean age was 41.4 years in the intervention group and 44.6 years in the control group $(\mathrm{p}=0.011)$. No differences were found between the PROMIS T-score of the intervention and control groups at baseline. However, the first contacted professional who used the booklet during the appointment differed significantly $(p=0.001$; Table 2). In the intervention group, the first contacted professional was a physician for $44 \%$ and a physiotherapist for $43 \%$ of the patients, in comparison to $28 \%$ and $62 \%$ in the control group, respectively. Only a few patients met both a physician and a nurse $(12 \%$ in the intervention and $9 \%$ in the control group). The first contacting professional was seldom a nurse alone $(0 \%$ in the intervention and $1 \%$ in the control group).

Table 1 Baseline characteristics of study population

\begin{tabular}{|c|c|c|c|c|}
\hline Characteristics & $\begin{array}{l}\text { Intervention } \\
(\mathrm{n}=212)\end{array}$ & $\begin{array}{l}\text { Control } \\
(n=203)\end{array}$ & $\begin{array}{l}\text { missing } \\
\%(n)\end{array}$ & $\begin{array}{l}\text { P value for difference between } \\
\text { intervention and control groups }\end{array}$ \\
\hline Age $^{a}$ (years) & $41.4(12.8)$ & $44.6(12.6)$ & $0(0)$ & 0.011 \\
\hline Gender female ${ }^{b}$ & $60.8(129)$ & $67.0(136)$ & $0(0)$ & 0.193 \\
\hline $\begin{array}{l}\text { Physically inactive } \\
\text { (light exercise } \leq 1 / \text { month) }\end{array}$ & $4.8(7)$ & $3.7(6)$ & $26.3(109)$ & 0.778 \\
\hline Body mass index ${ }^{a}\left(\mathrm{~kg} / \mathrm{m}^{2}\right)$ & $27.8(5.8)$ & $27.8(5.2)$ & $26.3(109)$ & 0.984 \\
\hline Smoking ${ }^{b}$ & $29.0(42)$ & $29.8(48)$ & $26.3(109)$ & 0.871 \\
\hline DEPS score ${ }^{c}$ & $5.0(8.0)$ & $6.0(8.5)$ & $26.3(109)$ & 0.118 \\
\hline Actively working ${ }^{b}$ & $57.9(84)$ & $56.5(91)$ & $26.3(109)$ & 0.804 \\
\hline Work ability ${ }^{c}(0-10)$ & $7.0(8.0)$ & $7.0(8.0)$ & $26.3(109)$ & 0.279 \\
\hline Comorbidity $^{b}$ & & & $26.9(112)$ & \\
\hline Diabetes & $3.5(5)$ & $9.3(15)$ & & 0.062 \\
\hline Rheumatoid arthritis & $1.4(2)$ & $1.9(3)$ & & 1.000 \\
\hline Spondylarthritis & 0 & $0.6(1)$ & & 1.000 \\
\hline Osteoarthritis & $18.2(26)$ & $25.5(41)$ & & 0.130 \\
\hline Depression & $17.5(25)$ & $22.4(36)$ & & 0.317 \\
\hline Fibromyalgia & $2.1(3)$ & $3.1(5)$ & & 0.727 \\
\hline Inflammatory bowel disease & $1.4(2)$ & $5.0(8)$ & & 0.110 \\
\hline Muscle disease & $0.7(1)$ & 0 & & 0.470 \\
\hline
\end{tabular}

a Mean (standard deviation), $\mathrm{p}$ value for between-group difference from independent-samples T-test

${ }^{b}$ Percentage (frequency), $p$ value for between-group difference from Chi-square test or Fisher's exact

${ }^{c}$ Median (interquartile range), $\mathrm{p}$ value for between-group difference from Mann-Whitney U-test

LBP (Low Back Pain), DEPS (Depression Scale) 
Table 2 Pain-related characteristics of the study population and first contacting professional during the study

\begin{tabular}{|c|c|c|c|c|c|}
\hline Characteristics & $\begin{array}{l}\text { Intervention } \\
(\mathrm{n}=212)\end{array}$ & Control $(n=203)$ & $\begin{array}{l}\text { P-value for the difference between } \\
\text { intervention and control groups }\end{array}$ & $\begin{array}{l}\text { Missing } \wedge \wedge \text { in } \\
\text { intervention } \\
\%(n)\end{array}$ & $\begin{array}{l}\text { Missing } \wedge \wedge \text { in } \\
\text { control \%(n) }\end{array}$ \\
\hline \multicolumn{6}{|l|}{ Electronic patient records data } \\
\hline First contacting professional $\wedge \%(n)^{2}$ & & & 0.001 & $10.8(23)$ & $9.4(19)$ \\
\hline Physician & $44.4(84)$ & $27.7(51)$ & & & \\
\hline Nurse and physician & $12.2(23)$ & $9.2(17)$ & & & \\
\hline Physiotherapist & $43.4(83)$ & $62.0(114)$ & & & \\
\hline Nurse alone & $0.0(0)$ & $1.1(2)$ & & & \\
\hline \multicolumn{6}{|l|}{ Baseline questionnaire data } \\
\hline $\begin{array}{l}\text { Back pain intensity during past week }{ }^{1} \text { (NRS, } \\
0-10 \text { ) }\end{array}$ & $5.1(2.4)$ & $4.9(2.5)$ & 0.455 & $31.6(67)$ & $20.7(42)$ \\
\hline $\begin{array}{l}\text { Leg pain intensity during past week (NRS } \\
0-10 \text { ) }\end{array}$ & $3.7(3.3)$ & $3.3(3.0)$ & 0.376 & $31.6(67)$ & $20.7(42)$ \\
\hline SBT total score ${ }^{1}$ & $4.5(2.3)$ & $4.6(2.3)$ & 0.702 & $31.6(67)$ & $20.7(42)$ \\
\hline SBT risk groups ${ }^{2}$ & & & 0.731 & $31.6(67)$ & $20.7(42)$ \\
\hline Low risk ${ }^{2}$ & $37.2(54)$ & $32.9(53)$ & & & \\
\hline Medium $^{2}$ & $40.0(50)$ & $42.9(69)$ & & & \\
\hline $\mathrm{High}^{2}$ & $22.8(33)$ & $24.2(39)$ & & & \\
\hline ÖMPSQ-short total score ${ }^{1}$ & $43.0(17.3)$ & $43.2(19.6)$ & 0.914 & $31.6(67)$ & $20.7(42)$ \\
\hline ÖMPSQ-short risk groups*2 & & & 0.615 & $31.6(67)$ & $20.7(42)$ \\
\hline Low risk ${ }^{2}$ & $48.3(70)$ & $44.1(71)$ & & & \\
\hline Medium $^{2}$ & $18.6(27)$ & $17.4(28)$ & & & \\
\hline $\mathrm{High}^{2}$ & $33.1(48)$ & $38.5(62)$ & & & \\
\hline Pain-related fear $(F A B Q)^{3}$ & $34.0(29.5)$ & $37.0(36.5)$ & 0.249 & $31.6(67)$ & $20.7(42)$ \\
\hline Pain-related fear (FABQ) -Work $k^{* * 3}$ & $13.0(17.0)$ & $16.0(21.5)$ & 0.213 & & \\
\hline Pain-related fear (FABQ) -Physical activity ${ }^{* * * 3}$ & $13.0(8.0)$ & $14.0(9.5)$ & 0.773 & & \\
\hline $\begin{array}{l}\text { Pain Self-Efficacy beliefs Questionnaire } \\
(\text { PSEQ) })^{3}\end{array}$ & $44.0(18.0)$ & $45.0(20.0)$ & 0.908 & $31.6(67)$ & $20.7(42)$ \\
\hline Physical functioning (PROMIS PF-20 T-score) ${ }^{1}$ & $44.7(6.7)$ & $43.8(7.4)$ & 0.271 & $34.3(73)$ & $25.1(51)$ \\
\hline Physical impairment, (RMDQ) $)^{3}$ & $5.0(7.0)$ & $6.0(8.0)$ & 0.049 & $37.3(79)$ & $29.6(60)$ \\
\hline Disability $(\mathrm{OD} / \%)^{1}$ & $23.9(8.4)$ & $24.1(8.9)$ & 0.832 & $31.6(67)$ & $20.7(42)$ \\
\hline Self-rated health status ${ }^{1}(1-100)$ & $67.1(21.1)$ & $67.2(20.8)$ & 0.953 & $31.9(68)$ & $20.7(42)$ \\
\hline LBP frequence (daily LBP yes/no) ${ }^{2}$ & $43.4(63)$ & $50.9(82)$ & 0.191 & $31.6(67)$ & $20.7(42)$ \\
\hline Duration of $L B P^{2}$ & & & 0.586 & $31.6(67)$ & $20.7(42)$ \\
\hline 3 weeks or less & $31.7(46)$ & $33.5(54)$ & & & \\
\hline 4 to 52 weeks & $44.8(65)$ & $47.8(77)$ & & & \\
\hline overone year & $23.4(35)$ & $18.6(30)$ & & & \\
\hline $\begin{array}{l}\text { Pain medication use } \geq 3 \text { days during past } \\
\text { week }^{2}\end{array}$ & $46.9(68)$ & $46.0(74)$ & 0.870 & $31.6(67)$ & $20.7(42)$ \\
\hline
\end{tabular}

${ }^{1}$ Mean (standard deviation), p-value for between-group difference from independent-samples T-test

${ }^{2}$ Percentage (frequency), p-value for between-group difference from Chi-square test

${ }^{3}$ Median (interquartile range), $\mathrm{p}$-value for between-group difference from Mann-Whitney U-test

$\wedge$ Contacts to other professional before and after study consent allowed

$\wedge \wedge$ Missing data include lost to follow-up

* Low-risk (0-39 points), Medium-risk (40-49 points) and High-risk (50-100 points)

** FABQ (Fear Avoidance Believes Questionnaire) work - items 6, 7, 9, 10, 11, 12, 15

${ }^{* * *}$ FABQ physical activity - items 2, 3, 4, 5

NRS (Numeral Rating Scale), SBT (Start-Back Tool), ÖMPSQ (Örebro Musculoskeletal Pain Screening Questionnaire), PSEQ (Pain Self Efficacy Questionnaire), PROMIS PS-20 T-score (Patient-Reported Outcomes Measurement Information System, 20-item physical functioning short form T-score), RMDQ-24 (Roland Morris Disability Questionnaire 24 form), ODI (Oswestry Disability Index)

** and *** Waddell G, Newton M, Henderson I, Somerville D, Main CJ. A Fear-Avoidance Beliefs Questionnaire (FABQ) and the role of fear-avoidance beliefs in chronic low back pain and disability. Pain. 1993 Feb;52(2):157-68 


\section{Intervention results}

\section{Primary outcomes}

The use of the patient education booklet appeared to substantially reduce the proportion of LBP patients who underwent an imaging examination at three months, but the result was not statistically significant (OR 0.57, 95\% confidence intervals $(\mathrm{Cl}) 0.27$ to $1.22, \mathrm{p}=0.147$ ) (Table 3 ). The proportion of patients presenting with LBP who had undergone imaging examinations due to LBP over three months was relatively low in both groups: $10.8 \%$ in the intervention and $16.7 \%$ in the control group.

The between-group difference in PROMIS PF-20 T-score change between baseline and three-month follow-up was not statistically significant (mean difference 1.0, 95\% CI -1.5 to $3.5, \mathrm{p}=0.365$ ) (Table 4 ). The intraclass correlation of PROMIS t-score change at three months was 0.00005 .

Table 3 Outcomes from electronic patient record data

\begin{tabular}{|c|c|c|c|c|}
\hline & Intervention group $\mathrm{n}=178$ & Control group $n=186$ & intervention vs control & $\begin{array}{l}\text { Age adjusted intervention vs } \\
\text { control }\end{array}$ \\
\hline & $\%(n)$ & $\%(n)$ & OR $(95 \% \mathrm{Cl}) ; \mathrm{P}$ value & OR $(95 \% \mathrm{CI}) ; \mathrm{P}$ value \\
\hline \multicolumn{5}{|c|}{ Imaging ${ }^{a}$ (yes/no) } \\
\hline 3 months & $10.8(19)$ & $16.7(31)$ & 0.57 (0.27 to 1.22$) ; 0.147$ & $0.60(0.29-1.24) ; 0.166$ \\
\hline 12 months & $17.5(31)$ & $29.7(54)$ & 0.50 (0.30 to 0.83$) ; 0.008$ & $0.52(0.32$ to 0.84$) ; 0.007$ \\
\hline \multicolumn{5}{|c|}{ Radiographs $^{\mathrm{a}}$} \\
\hline 3 months & $5.6(10)$ & $9.1(17)$ & 0.57 (0.25 to 1.29$) ; 0.178$ & $0.58(0.25-1.33) ; 0.199$ \\
\hline 12 months & $8.4(15)$ & $14.7(27)$ & 0.55 (0.34 to 0.88$) ; 0.013$ & $0.58(0.37$ to 0.90$) ; 0.016$ \\
\hline \multicolumn{5}{|c|}{$\begin{array}{l}\text { Magnetic resonance imaging } \\
(\mathrm{MRI})^{\mathrm{a}}\end{array}$} \\
\hline 3 months & $7.3(13)$ & $8.6(16)$ & 0.86 (0.49 to 1.52$) ; 0.610$ & $0.90(0.55-1.48) ; 0.688$ \\
\hline 12 months & $12.8(23)$ & $21.1(39)$ & $0.61(0.44$ to 0.84$) ; 0.002$ & $0.64(0.49$ to 0.84$) ; 0.001$ \\
\hline \multicolumn{5}{|c|}{ Computed tomography $(\mathrm{CT})^{\text {a }}$} \\
\hline 3 months & $0(0)$ & $1.6(3)$ & c & c \\
\hline 12 months & $0.6(1)$ & $2.2(4)$ & c & c \\
\hline \multicolumn{5}{|l|}{$\mathrm{MRI}+\mathrm{CT}^{\mathrm{a}}$} \\
\hline 3 months & $7.3(13)$ & $9.1(17)$ & 0.81 (0.45 to 1.46$) ; 0.475$ & $0.86(0.51-1.4) ; 0.555$ \\
\hline \multirow[t]{2}{*}{12 months } & $13.4(24)$ & $21.7(40)$ & $0.60(0.39$ to 0.91$) ; 0.016$ & $0.64(0.45$ to 0.91$) ; 0.014$ \\
\hline & mean(SD); sum & mean(SD); sum & RR (95\% Cl); P-value & RR (95\% CI); P-value \\
\hline \multicolumn{5}{|c|}{ Sick leave days ${ }^{b}$} \\
\hline 3 months & $3.8(11.2) ; 664$ & $8.4(20.2) ; 1526$ & $0.47(0.26$ to 0.83$) ; 0.010$ & $0.48(0.29$ to 0.81$) ; 0.006$ \\
\hline 12 months & $7.5(31.3) ; 1330$ & $20.8(59.2) ; 3717$ & $0.36(0.18$ to 0.72$) ; 0.004$ & $0.39(0.22-0.70) ; 0.002$ \\
\hline \multicolumn{5}{|c|}{ Physician appointments ${ }^{b}$} \\
\hline 3 months & $1.1(1.4) ; 156$ & $1.2(1.5) ; 188$ & $0.92(0.44$ to 1.9$) ; 0.813$ & 0.92 (0.44 to 1.9$) ; 0.822$ \\
\hline 12 months & $1.6(2.1) ; 231$ & $1.8(2.3) ; 283$ & 0.87 (0.4 to 1.9); 0.725 & $0.87(0.41$ to 1.78$) ; 0.678$ \\
\hline \multicolumn{5}{|c|}{ Physiotherapist appointments ${ }^{b}$} \\
\hline 3 months & $1.2(1.7) ; 212$ & $1.3(1.1) ; 235$ & $0.88(0.56$ to 1.40$) ; 0.601$ & 0.89 (0.55 to 1.43$) ; 0.618$ \\
\hline 12 months & $1.7(2.6) ; 297$ & $2.0(2.2) ; 359$ & $0.83(0.55$ to 1.2$) ; 0.356$ & $0.83(0.56$ to 1.23$) ; 0.829$ \\
\hline \multicolumn{5}{|c|}{ Nurse appointments ${ }^{b}$} \\
\hline 3 months & $0.3(1.2) ; 60$ & $0.2(0.7) ; 41$ & 1.3 (0.20 to 8.42); 0.772 & 1.3 (0.20 to 9.69$) ; 0.749$ \\
\hline 12 months & $0.6(1.8) ; 107$ & $0.3(1.0) ; 60$ & $1.72(0.34$ to 8.66$) ; 0.514$ & 1.93 (0.34 to 11.04$) ; 0.458$ \\
\hline \multicolumn{5}{|c|}{$\begin{array}{l}\text { Secondary health care } \\
\text { appointments (physia- } \\
\text { trist + orthopedist) }\end{array}$} \\
\hline 3 months & $0.3(1.0) ; 48$ & $0.3(0.7) ; 55$ & 1.06 (0.68 to 1.65$) ; 0.801$ & 1.10 (0.73 to 1.64$) ; 0.662$ \\
\hline 12 months & $0.6(1.6) ; 87$ & $0.7(1.8) ; 132$ & 0.81 (0.49 to 1.35$) ; 0.426$ & 0.84 (0.53 to 1.33$) ; 0.447$ \\
\hline
\end{tabular}

${ }^{a}$ Difference between intervention and control groups analysed with logistic regression using generailzed estimating equations with exchangeable working correlation matrix

${ }^{b}$ Difference between intervention and control groups analysed with Poisson regression using general estimating equations with exchangeable working correlation matrix

Odds Ratio (OR), Confidence Interval (Cl), Risk Ratio (RR)

${ }^{\mathrm{C}} \mathrm{OR}$ not possible due to zero frequency 


\section{Secondary outcomes}

The proportion of patients who underwent any imaging over the 12-month follow-up was lower in the intervention group. The imaging rate over 12 months was $17.5 \%$ in the intervention and $29.7 \%$ in the control group (OR $0.50,95 \% \mathrm{Cl} 0.30$ to $0.83, \mathrm{p}=0.008$ ). Similar results were found when radiographs and MRI were analysed separately (at 12 months radiographs (OR $0.55,95 \% \mathrm{Cl} 0.34$ to $0.88, \mathrm{p}=0.013$ ) and MRI (OR $0.61,95 \% \mathrm{Cl} 0.44$ to 0.84 , $\mathrm{p}=0.002)$ ). The results were similar in the age-adjusted analyses (Table 3).

The mean number of sick leave days was 3.8 days in the intervention group and 8.4 days in the control group for the first three months, and 7.5 and 20.8 days, respectively, for the whole 12-month period. The differences in sick leave days were statistically significant over the 3-month (RR 0.47, 95\% CI 0.26 to $0.83, \mathrm{p}=0.010$ ) and 12-month follow-ups (RR $0.36,95 \% \mathrm{Cl} 0.18$ to $0.72, \mathrm{p}=0.004$; Table 3).

There were no statistically significant differences between the groups in the number of health care appointments (Table 3) or patient-reported secondary outcomes: physical functioning (PROMIS T-score), back or leg pain intensity, disability (ODI), quality of life (EQ$5 \mathrm{D})$, self-rated health (EQ VAS) or frequency of daily LBP (Table 4).

\section{Sensitivity analyses}

Sensitivity analyses were conducted on the basis of the first contacted professional (e.g., physician or physiotherapist), because of the large baseline differences and the likelihood that the effects of the intervention would be different across the different professionals (Table 5). When the first contacted professional was a physician, $7 \%$ of the patients underwent imaging examinations over the first three months in the intervention group, in comparison with $29 \%$ in the control group (OR $0.15,95 \%$ CI 0.09 to $0.24, p<0.001)$. Over 12 months, the proportion of imaging use was $15.7 \%$ in the intervention group and $42 \%$ in the control group (OR 0.23, 95\% CI 0.16 to $0.33, p<0.001$ ). The intervention had no effect on PROMIS PF-20 change between baseline and 3-month or 12-month follow-up. In addition, when the first contacted professional was a physician, the intervention reduced sick leave days to one third at both 3 months (RR $0.35,95 \% \mathrm{Cl} 0.20$ to 0.64 , $\mathrm{p}=0.001$ ) and 12 months (RR 0.34, 95\% Cl 0.23 to 0.51 , $p<0.001)$. The risk of further physician appointments decreased by one third at both 3 months (RR 0.65, 95\% $\mathrm{Cl} 0.55$ to $0.75, p<0.001$ ) and 12 months (RR $0.60,95 \% \mathrm{Cl}$ 0.49 to $0.72, p<0.001)$. The number of secondary health care appointments was lower at both 3 months (RR 0.79, $95 \% \mathrm{Cl} 0.75$ to $0.82, p<0.001$ ) and 12 months (RR 0.91, $95 \% \mathrm{Cl} 0.88$ to $0.95, p<0.001)$.
When the first contacted professional was a physiotherapist, the differences in imaging rates were not significant (3 months OR 1.23, 95\% CI 0.30 to 5.61, $\mathrm{p}=0.729 ; 12$ months OR $0.91,95 \% \mathrm{CI} 0.37$ to 2.25 , $\mathrm{p}=0.842$ ). The PROMIS PF-20 T-score differed significantly at baseline when the first contacted professional was a physiotherapist, but the intervention was no more effective than usual care at 3-month or 12-month followup. However, the number of sick leave days decreased to one quarter in the intervention group at 3 months (RR $0.24,95 \% \mathrm{Cl} 0.09-0.71, \mathrm{p}=0.010)$ and to one fifth at 12 months (RR $0.17,95 \% \mathrm{Cl} 0.07$ to $0.45, p<0.001$ ). Similarly, if the physiotherapists used the booklet as part of care, physician appointments decreased at three months (RR $0.39,95 \% \mathrm{Cl} 0.18$ to $0.84, \mathrm{p}=0.017$ ). At 12 months, the difference was smaller and no longer statistically significant ( $\mathrm{RR} 0.72,95 \% \mathrm{Cl} 0.27$ to $1.89, \mathrm{p}=0.501$ ). There were no between-group differences in other secondary outcomes among the patients who first saw a physiotherapist.

The combination of a physician and nurse as the first contacted professional was uncommon $(11 \%(n=23)$ in the intervention group and $8 \%(n=17)$ in the control group), and occurred in only two of the eight clusters. The sensitivity analyses of the effect of using the patient education booklet during an LBP patient appointment within this subgroup is presented in Additional file 4.

\section{Discussion}

Key findings

The use of the patient education booklet to support evidence-based care of LBP patients in primary care appeared to substantially reduce the proportion of imaging at three months; however, this was only statistically significant when a physician was the first contacted professional. The impact of using the education booklet on imaging rates was substantial at 12 months, with a reduction in imaging proportions of $50 \%$ in the intervention group compared to the control group. In the other primary outcome of change in PROMIS T-score, we found no difference between the intervention and control groups. In the secondary outcome of sick leave days, we observed a significant reduction both at 3 months (RR $0.4795 \%$ CI 0.26 to $0.83, \mathrm{p}=0.010$ ) and 12 months (RR 0.36 95\% CI 0.18 to 0.72 , $\mathrm{p}=0.004$ ).

Radiographic imaging rates were low in both the intervention and control groups (radiograph rate $8 \%$ in the intervention and $15 \%$ in the control group, MRI rate $13 \%$ and $21 \%$, respectively) compared to a previous systematic review, in which $31 \%$ of patients underwent radiograph imaging due to LBP in primary care over one year, whereas $16 \%$ received MRI [24]. This 
Table 4 Patient reported outcomes

\begin{tabular}{|c|c|c|c|c|c|c|c|c|c|}
\hline Outcome & Time & $\begin{array}{l}\text { Intervention } \\
\text { group } \\
n \text { (total } \\
n=145 \text { ) }\end{array}$ & $\begin{array}{l}\text { Control } \\
\text { group } \\
n \text { (total } \\
n=161 \text { ) }\end{array}$ & $\begin{array}{l}\text { Intervention } \\
\text { group } \\
\text { Mean }^{\mathrm{a}}(\mathrm{SE})\end{array}$ & $\begin{array}{l}\text { Control } \\
\text { group } \\
\text { Mean }^{\mathrm{a}} \text { (SE) }\end{array}$ & $\begin{array}{l}\text { Mean } \\
\text { difference }^{b} \\
(95 \% \mathrm{Cl})\end{array}$ & $P$ value & $\begin{array}{l}\text { Age-adjusted } \\
\text { mean difference } \\
(95 \% \mathrm{Cl})\end{array}$ & P value \\
\hline \multirow{3}{*}{$\begin{array}{l}\text { PROMIS } \\
\text { T-score }^{b}\end{array}$} & Baseline & 139 & 152 & $44.7(0.6)$ & $43.8(0.6)$ & $0.9(-0.7$ to 2.6$)$ & 0.271 & $0.5(-1.1$ to 2.1$)$ & 0.526 \\
\hline & Change $3 \mathrm{~m}$ & 84 & 95 & $2.5(0.7)$ & $1.5(0.7)$ & $1.0(-1.5$ to 3.5$)$ & 0.365 & $0.93(-1.0$ to 2.9$)$ & 0.346 \\
\hline & Change $12 \mathrm{~m}$ & 67 & 91 & $2.2(0.9)$ & $2.3(0.7)$ & $-0.1(-2.3$ to 2.1$)$ & 0.923 & 0.09 (-2.3 to 2.2$)$ & 0.935 \\
\hline \multirow{3}{*}{$\begin{array}{l}\text { Low back pain } \\
\text { intensity dur- } \\
\text { ing last week } \\
(\mathrm{NRS}, 0-10)^{b}\end{array}$} & Baseline & 145 & 161 & $5.1(0.3)$ & $4.8(0.3)$ & $0.29(-0.8$ to 1.3$)$ & 0.521 & $0.38(-0.7$ to 1.5$)$ & 0.427 \\
\hline & Change 3 m & 91 & 105 & $-0.6(0.5)$ & $-0.4(0.5)$ & $-0.3(-2.1$ to 1.5$)$ & 0.732 & $-0.3(-2.1$ to 1.5$)$ & 0.695 \\
\hline & Change $12 \mathrm{~m}$ & 79 & 105 & $-1.8(0.5)$ & $-1.3(0.5)$ & $-0.47(-2.1$ to 1.2$)$ & 0.517 & $-0.5(-2.2$ to 1.1$)$ & 0.462 \\
\hline \multirow{3}{*}{$\begin{array}{l}\text { Leg pain inten- } \\
\text { sity during last } \\
\text { week LN [(NRS } \\
0-10)+0.5]^{\mathrm{e} b}\end{array}$} & Baseline & 145 & 161 & $0.9(0.1)$ & $0.9(0.1)$ & $0.1(-0.4$ to 0.5$)$ & 0.805 & $0.1(-0.4$ to 0.6$)$ & 0.708 \\
\hline & Change 3 m & 91 & 105 & $-0.2(0.2)$ & $0.01(0.2)$ & $-0.2(-0.8$ to 0.4$)$ & 0.407 & $-0.2(-0.8$ to 0.4$)$ & 0.395 \\
\hline & Change $12 \mathrm{~m}$ & 79 & 105 & $0.4(0.2)$ & $-0.2(0.1)$ & $-0.1(-0.7$ to 0.4$)$ & 0.506 & $-0.2(-0.7$ to 0.4$)$ & 0.491 \\
\hline \multirow[t]{3}{*}{ ODI\% ${ }^{\mathrm{b}}$} & Baseline & 145 & 161 & $23.5(1.3)$ & $24.0(1.2)$ & $-0.5(-4.0$ to 3.1$)$ & 0.795 & $0.2(-3.4$ to 3.7$)$ & 0.925 \\
\hline & Change $3 \mathrm{~m}$ & 91 & 105 & $-5.1(1.8)$ & $-3.4(1.7)$ & $-1.7(-7.6$ to 4.1$)$ & 0.501 & $-1.7(-7.6$ to 4.1$)$ & 0.511 \\
\hline & Change 12 m & 79 & 104 & $-5.7(2.4)$ & $-4.1(2.2)$ & $-1.6(-10.1$ to 6.9$)$ & 0.645 & $-1.7(-10.2$ to 6.7$)$ & 0.619 \\
\hline \multirow[t]{2}{*}{$\begin{array}{l}\text { EQ5D-3L } \\
\text { index }{ }^{d b}\end{array}$} & Baseline & 145 & 161 & $0.659(0.023)$ & $0.664(0.022)$ & $\begin{array}{l}-0.005(-0.089 \text { to } \\
0.080)\end{array}$ & 0.890 & $\begin{array}{l}<0.001(<0.001 \text { to } \\
0.084)\end{array}$ & 0.807 \\
\hline & Change $12 \mathrm{~m}$ & 79 & 107 & $0.048(0.029)$ & $0.053(0.025)$ & $\begin{array}{l}0.005(-0.081 \text { to } \\
0.071)\end{array}$ & 0.894 & $\begin{array}{l}-0.007(-0.083 \text { to } \\
0.070)\end{array}$ & 0.859 \\
\hline \multirow{3}{*}{$\begin{array}{l}\text { Self-rated } \\
\text { health EQ5D- } \\
\text { VAS }(0-100)^{b}\end{array}$} & Baseline & 144 & 159 & $68.2(2.5)$ & $67.1(2.4)$ & 1.1 (-7.3 to 9.4$)$ & 0.771 & 0.5 (-7.9 to 8.8$)$ & 0.899 \\
\hline & Change $12 \mathrm{~m}$ & 75 & 103 & $5.4(2.4)$ & $5.6(2.1)$ & -0.1 (-6.5 to 6.2$)$ & $0-970$ & 0.03 (-6.4 to 6.4$)$ & 0.992 \\
\hline & & & & $\%(n)$ & $\%(n)$ & OR $(95 \% \mathrm{Cl})$ & & OR $(95 \% \mathrm{Cl})$ & \\
\hline \multirow{3}{*}{$\begin{array}{l}\text { LBP frequency } \\
\text { (daily LBP yes/ } \\
\text { no })^{c}\end{array}$} & Baseline & 147 & 161 & $43.4(63)$ & $50.9(82)$ & 0.79 (0.57 to 1.09 ) & 0.143 & 0.80 (0.55 to 1.16$) ;$ & 0.244 \\
\hline & 3 months & & & $38.7(36)$ & $42.6(46)$ & 0.94 (0.61 to 1.44 ) & 0.768 & 0.94 (0.50 to 1.49 ) & 0.792 \\
\hline & 12 months & 83 & 107 & $28.9(24)$ & $32.7(35)$ & 0.85 (0.48 to 1.51$)$ & 0.586 & 0.84 (0.48 to 1.49 ) & 0.560 \\
\hline
\end{tabular}

Presented as intervention group vs control group. ${ }^{a}$ Values estimated from least square means with standard error. ${ }^{b}$ Least square mean difference estimated from linear mixed model with random effects for unit. Positive and negative mean differences indicate higher and lower values among intervention group, respectively. ${ }^{c}$ Difference between intervention and control groups analyzed with logistic regression using generalized estimating equations with exchangeable working correlation matrix

Change $3 \mathrm{~m}$ calculated from baseline to 3-month follow-up and change $12 \mathrm{~m}$ from baseline to 12-month follow-up

d UKTTO

NRS (Numeral rating scale), ODI (Oswestry Disability Index), PROMIS T-score (Patient-Reported Outcomes Measurement Information System, 20-item physical functioning short form T-score), EQ5D-3L index (EuroQol five dimensions, 3-level version)

e LN (natural logarithmic) transformation for Leg pain intensity used because of positively skewed distribution

difference may be explained by the profession of the first contacted professional. When the first contacted professional was a physician, the radiographic imaging rate over 12 months was $8 \%$ in the intervention group and $24 \%$ in the control group. In contrast, when physiotherapists were the first contacted professional, radiograph imaging use was $9 \%$ in the intervention group and $12 \%$ in the control group. In the Finnish health care system, physiotherapists cannot directly refer patients for imaging, which likely explains the lower imaging proportions and the stronger reduction in imaging in the sub-group of patients who contacted a physician first (OR $0.15,95 \%$ CI 0.09 to 0.24 ). In addition, also the probability of severity of disease might differ according to the first contacting professional, which we are unable to evaluate in our data. The total (including all imaging modalities) imaging rate was lower in both groups at three months $(11 \%$ in the intervention and $17 \%$ in the control group) than we expected in sample-size calculations (30\%). This reduced the statistical power to detect significant differences at that time point. The results at three months indicated a trend towards less imaging in the intervention group. The effect sizes at 3 months and 12 months 
Table 5 Sensitivity analyses according to first contacted professional

\begin{tabular}{|c|c|c|c|c|c|c|}
\hline \multirow{3}{*}{$\begin{array}{l}\text { First contacted } \\
\text { professional } \\
\text { Imaging (yes/no) }^{\mathrm{a}}\end{array}$} & \multicolumn{3}{|c|}{ Physician (Intervention $n=84$, control $n=51$ ) } & \multicolumn{3}{|c|}{ Physiotherapist (Intervention $n=67$, control $n=114$ ) } \\
\hline & \multirow{2}{*}{$\begin{array}{l}\text { Intervention } \\
\%(n)\end{array}$} & \multicolumn{2}{|l|}{ Control } & \multirow{2}{*}{$\begin{array}{l}\text { Intervention } \\
\%(n)\end{array}$} & \multicolumn{2}{|l|}{ Control } \\
\hline & & $\%(n)$ & OR ( $95 \% \mathrm{Cl})$; P value & & $\%(n)$ & OR (95\% Cl); P value \\
\hline Imaging 3 months & $7.3(6)$ & $29.4(15)$ & $0.15(0.09-0.24) ;<0.001$ & $10.4(7)$ & $11.4(13)$ & $1.23(0.30-5.61) ; 0.729$ \\
\hline Imaging 12 months & $15.7(13)$ & $42(21)$ & $0.23(0.16-0.33) ;<0.001$ & $17.9(12)$ & $22.3(25)$ & $0.91(0.37-2.25) ; 0.842$ \\
\hline Radiographs 3 months & $6.0(5)$ & $19.6(10)$ & $0.21(0.19-0.23) ;<0.001$ & $4.5(3)$ & $6.1(7)$ & $0.88(0.17-4.57) ; 0.882$ \\
\hline Radiographs 12 months & $8.3(7)$ & $23.5(12)$ & $0.28(0.25-0.31) ;<0.001$ & $9.0(6)$ & $12.4(14)$ & $0.79(0.31-2.02) ; 0.616$ \\
\hline $\begin{array}{l}\text { Magnetic resonance imaging } \\
\text { (MRI) } 3 \text { months }\end{array}$ & $3.6(3)$ & $13.7(7)$ & $0.17(0.09-0.32) ;<0.001$ & $8.7(6)$ & $5.3(6)$ & $1.76(0.57-5.48) ; 0.329$ \\
\hline MRI 12 months & $9.5(8)$ & $23.5(12)$ & $0.33(0.16-0.70) ; 0.004$ & $15.9(11)$ & $16.8(19)$ & $0.91(0.48-1.71) ; 0.760$ \\
\hline PROMIS T-score ${ }^{b}$ & Mean (SE) & Mean (SE) & $\begin{array}{l}\text { Mean difference }(\mathrm{Cl}) ; \mathrm{P} \\
\text { value }\end{array}$ & Mean (SE) & Mean (SE) & Mean difference $(\mathrm{Cl})$; $\mathrm{P}$ value \\
\hline Baseline & $42.8(1.0)$ & $42.2(1.2)$ & $0.60(-3.9$ to 5.1$) ; 0.713$ & $45.9(0.9)$ & $44.9(0.8)$ & $1.1(-1.4$ to 3.5$) ; 0.391$ \\
\hline Change $3 \mathrm{~m}$ & $3.1(1.1)$ & $1.3(1.2)$ & $1.87(-1.4$ to 5.1$) ; 0.254$ & $2.2(1.0)$ & $1.3(0.8)$ & $0.9(-1.7$ to 3.6$) ; 0.488$ \\
\hline Change $12 \mathrm{~m}$ & $2.7(1.7)$ & $1.3(1.8)$ & $1.44(-5.0$ to 7.9$) ; 0.591$ & $1.7(1.7)$ & $2.6(1.3)$ & -0.9 (-8.7 to 6.8$) ; 0.704$ \\
\hline Sick leave days ${ }^{c}$ & Mean (SD) & Mean (SD) & RR (95\% Cl); P value & Mean (SD) & Mean (SD) & RR (95\% Cl); P value \\
\hline 3 months & $4.9(10.6)$ & $13.0(23.2)$ & $0.35(0.20-0.64) ; 0.001$ & $1.4(7.8)$ & $7.7(21.6)$ & $0.24(0.09-0.71) ; 0.010$ \\
\hline 12 months & $6.9(16.7)$ & $16.0(30.1)$ & $0.34(0.23-0.51) ;<0.001$ & $4.5(17.9)$ & $28.6(78.6)$ & $0.17(0.07-0.45) ;<0.001$ \\
\hline \multicolumn{7}{|l|}{$\begin{array}{l}\text { LBP-related health care } \\
\text { appointments }{ }^{c}\end{array}$} \\
\hline Physician 3 months & $1.6(1.5)$ & $2.2(1.4)$ & $0.65(0.55-0.75) ;<0.001$ & $0.3(0.6)$ & $0.6(1.2)$ & $0.39(0.18-0.84) ; 0.017$ \\
\hline Physician 12 months & $2.0(2.2)$ & $3.0(2.0)$ & $0.60(0.49-0.72) ;<0.001$ & $0.9(1.7)$ & $1.2(2.3)$ & $0.72(0.27-1.89) ; 0.501$ \\
\hline Physiotherapist 3 months & $0.8(1.3)$ & $0.6(0.93)$ & $0.90(0.59-1.58) ; 0.897$ & $2.0(1.2)$ & $1.6(0.9)$ & $1.29(1.16-1.43) ;<0.001$ \\
\hline Physiotherapist 12 months & $1.3(2.6)$ & $1.2(1.6)$ & $0.80(0.47-1.37) ; 0.417$ & $2.8(2.1)$ & $2.4(2.6)$ & $1.05(1.02-1.09) ;<0.001$ \\
\hline Nurse 3 months & $0.3(0.8)$ & $0.1(0.4)$ & $1.22(0.22-6.81) ; 0.823$ & $0.1(0.3)$ & $0.1(0.3)$ & 1.39 (0.39-4.99); 0.617 \\
\hline Nurse 12 months & $0.8(1.7)$ & $0.2(0.7)$ & $1.73(0.39-7.77) ; 0.474$ & $0.3(1.5)$ & $0.1(0.3)$ & $5.19(1.16-23.3) ; 0.031$ \\
\hline $\begin{array}{l}\text { Secondary health care } \\
3 \text { months }\end{array}$ & $0.37(0.92)$ & $0.39(0.67)$ & $0.79(0.75-0.82) ;<0.001$ & $0.2(0.9)$ & $0.3(0.6)$ & $0.86(0.30-2.50) ; 0.783$ \\
\hline $\begin{array}{l}\text { Secondary health care } \\
12 \text { months }\end{array}$ & $0.57(1.17)$ & $0.53(0.98)$ & $0.91(0.88-0.95) ;<0.001$ & $0.6(1.4)$ & $0.8(2.1)$ & $0.84(0.34-2.08) ; 0.699$ \\
\hline
\end{tabular}

Presented as intervention group vs control group. ${ }^{a}$ Difference between intervention and control groups analysed with logistic regression using generalized estimating equations with exchangeable working correlation matrix. ${ }^{b}$ Least square mean difference estimated from linear mixed model with random effects for unit. Positive and negative mean differences indicate higher and lower values among intervention group, respectively. 'Difference between intervention and control groups analysed with Poisson regression using general estimating equations with exchangeable working correlation matrix

are very similar, despite differences in significance due to lower power at three months.

\section{Comparison with previous literature}

To our knowledge, the effectiveness of an intervention developed to address both physician- and patient-related barriers to reducing the use of imaging has not previously been tested. Previous studies have demonstrated reduced imaging examinations with the inclusion of epidemiologic data in lumbar spine MRI reports [25-27]. In our study, information on the usefulness of imaging was provided to all the patients and professionals, regardless of whether or not imaging was undertaken.

Interesting findings from secondary outcomes include the reduction in sick leave days at 3- and 12-month follow-ups. According to Ree et al. (2016), a workplace educational back pain intervention also reduced sick leave for up to six months [28]. In addition, in an occupational setting, booklet information alone was cost-effective in comparison to no intervention among patients with mild LBP [29]. Decreasing imaging may also enhance reductions in sick leaves. Previous research showed that decreased imaging for LBP was associated with decreased health care utilization and sick leave days [30,31]. In contrast to imaging, where an effect was observed only when a physician was the first contact, sick leave days also decreased when a physiotherapist was the first contacted professional. This is likely explained by physiotherapists' ability to grant short-term (up to five days) sick leave due to LBP in Finland. 
We used an average proportion of imaging (30\%) for sample size calculation, which was later seen to be significantly higher than the proportion of imaging in the control group at 3 months (16.7\%). According to previous literature, there is a wide variance in imaging proportions between different studies [5]. In this study, imaging proportions were likely decreased by the inclusion of physiotherapists, who can't directly refer patients for imaging, as first contact health care providers. A larger portion of control group patients saw a physiotherapist first compared to the intervention group. When the first contacting professional was a physician, the proportion of imaging at 3 months was $29.4 \%$ (Table 5).

\section{Interpretation of findings}

These results are consistent with the findings of the preliminary evaluation: the intervention reminded the professionals of the imaging guidelines and made it easier to follow them, and patient-related barriers were addressed by helping patients understand and receive an explanation for their pain [15]. It is possible that the shared-decision making and the written information supported decisions related to imaging use, and sustained, or even strengthened, the results over the 12-month follow-up. Common physician-reported reasons for using imaging include feeling that there is no alternative to imaging to offer the patient, and the lack of time to have a conversation with patients about diagnosis and why a scan is not needed [12]. The booklet provides practitioners with an alternative way to discuss the use of imaging with patients. It was easy to carry out, made sense to both the professionals and the patients, and supported evidence-based care.

The use of the patient education booklet in addition to usual care had no apparent effect on patients' pain, physical functioning, disability or quality of life in comparison to usual care. This may have needed a more intensive and probably a more individualized intervention.

\section{Implications of the findings}

The booklet appeared effective in reducing imaging and sick leave days among LBP patients in primary care and is suitable for implementation in similar primary care settings for this purpose. The patient education booklet is easy to use, inexpensive and seems to have no negative side effects, which endorses its implementation in practice. More research is needed to evaluate its effectiveness in different health care settings.

\section{Strengths and limitations}

One strength of this study is that we used a cluster randomized design, and assessed the effectiveness of the booklet in an everyday clinical environment in the Finnish health care system. Several elements enhanced the generalization of the results and the possibility to use the intervention in different primary care organizations in future studies: the low number of exclusion criteria for LBP patients; inviting all physicians and physiotherapists in the study health care regions or organizations to participate; easy implementation procedure; low costs of the intervention; and minimal or no suspected harm related to the intervention.

A limitation of the current study was that some patients saw a physician first and others saw a physiotherapist first. We therefore conducted sensitivity analyses, which found a stronger effect on imaging rates when the booklet was used by a physician. In this subgroup, it additionally reduced subsequent LBP-related physician appointments in primary care by one third and LBP-related secondary health care appointments by about $10 \%$. A systematic review and meta-analysis has earlier shown education for patients with acute or subacute LBP to reduce health care use (NNT 17 to prevent one primary health care physician visit due to LBP) [32].

The low number of clusters (eight) is also a limitation of the study. The health care policies of the clusters might have differed, even though we used suitable statistical methods for cluster randomized studies. For example, physicians' sick-leave practices have shown to vary significantly [33]. In addition, no information was recorded on the number of eligible LBP patients who declined to participate in the study, or on whether the professionals neglected to invite some eligible patients to the study, despite being asked to recruit consecutive eligible patients. Both of these could have introduced selection bias. The loss to follow-up for the patient-reported outcomes is a major limitation in estimating PROMIS PF-20 change between baseline and three-month followup, one of the two primary outcomes, due to its potential to bias the results of this study. Therefore, conclusions related to the effect of the booklet on physical function are limited. Data collection from the electronic patient records in addition to the patient reported data is a strength of the study. Loss to follow-up for the other primary outcome, imaging at three months, was relatively low. The results and conclusions related to imaging, were not prone to the limitations potentially caused by loss to follow-up for the patient-reported outcomes.

The intervention group was provided with guideline recommendations as part of the training they received to use the booklet. Provision of guideline recommendations as a single strategy to reduce imaging for low back pain has not previously shown evidence of effectiveness [34], potentially because provision of guidelines does not sufficiently address all identified barriers to adherence to 
clinical guidelines [35]. The intervention in this trial was designed to address identified barriers, including both poor practitioner knowledge of guideline recommendations and pressure from patients to receive imaging. In the preliminary evaluation study $81 \%$ of professionals agreed that the booklet helped them to adhere to imaging guidelines [15]. The aim of this study was to assess the combination of the booklet and training session as a complete intervention, rather than identify the effect of the separate components.

One further limitation is that we did not evaluate how the health professionals used the booklet in the consultations or whether using the intervention increased consultation times, this would be an important area of future study.

\section{Conclusions}

The booklet appeared effective in reducing the proportion of LBP patients who undergo imaging examinations when delivered by a physician. The intervention appeared to have no effect on PROMIS PF20 T-score change. The number of sick leave days appeared substantially lower in the intervention group.

\begin{abstract}
Abbreviations
BBQ: Back Beliefs Questionnaire; CI: Confidence interval; CS: Cluster size; MID: Minimal Important Difference; CT: Computed tomography; CV: Coefficient of variation of cluster size; DE: Design Effect; DEPS: Depression Scale; EQ-5D: EuroQol EQ-5D-3L instrument; FABQ: Fear avoidance beliefs questionnaire; GEE: Generalized estimating equations; ICC: Intracluster Correlation Coefficient; ICERs: Incremental cost-effectiveness ratios; LBP: Low back pain; MID: Minimal Important Difference; MRI: Magnetic resonance imaging; NRS: Numeral Rating Scale; ODI: Oswestry Disability Index; ÖMPSQ: Örebro Musculoskeletal Pain Screening Questionnaire; OR: Odds ratio; PROMIS PF-20: Patient-Reported Outcomes Measurement Information System, 20-item physical functioning short form; PSEQ: Pain Self-efficacy Questionnaire; RMDQ-24: Roland Morris Disability Questionnaire 24 form; RR: Risk ratio; SBT: STarT Back Tool; SD: Standard deviation.
\end{abstract}

\section{Supplementary Information}

The online version contains supplementary material available at https://doi. org/10.1186/s12875-021-01529-2.

\section{Additional file 1.}

Additional file 2.

Additional file 3.

Additional file 4.

\section{Acknowledgements}

We thank all the participating health care units, Research Assistants Mirjami Kutvonen and Marjo Pyyny, and Biostatistician Tero Vahlberg for his excellent statistical advice.

\section{Authors' contributions}

ASS, HJ, AM, MH, NB and JK participated in the design of the trial and the drafting of the manuscript. All the authors have read and approved the final manuscript.

\section{Funding}

Short-term Doctoral Student Positions 2018-2021 (6 month each year) are funded by the University of Oulu Health and Biosciences Doctoral Program (ASS). Funding for the research assistant in Mikkeli was granted by ESSOTE (South Savo social and health care authority). State Research Funding was granted for research assistant costs in Rovaniemi. ASS has received grants from the Finnish Cultural Foundation (ASS).

\section{Availability of data and materials}

The datasets used and analysed during the current study available from the corresponding author on reasonable request.

\section{Declarations}

\section{Ethics approval and consent to participate}

All methods were carried out in accordance with the Declaration of Helsinki. The study was approved by the Ethics Committee of the University Hospital of Oulu, and all participants provided informed written consent. Personal information was kept in secured repositories and replaced with ID codes in all analyses. ASS, JK and research assistants have access to the final trial dataset using a secured username and password.

\section{Consent for publication}

The manuscript does not include any individual person's data.

\section{Competing interests}

The authors declare that they have no competing interests.

\section{Author details}

${ }^{1}$ Medical Research Center Oulu, Oulu University Hospital and University of Oulu, P.O. Box 8000, 90014 Oulu, Finland. ${ }^{2}$ Department of General Medicine, the South Savo Social and Health Care Authority, Porrassalmenkatu 35-37, 50100 Mikkeli, Finland. ${ }^{3}$ Department of Health Professions, Faculty of Medicine, Health, and Human Sciences, Macquarie University, Balaclava Road, North Ryde, NSW 2109, Australia. ${ }^{4}$ Department of Chiropractic, Faculty of Medicine, Health, and Human Sciences, Macquarie University, Balaclava Road, North Ryde, NSW 2109, Australia. ${ }^{5}$ Finnish Institute for Health and Welfare, P.O. Box 30 , 00271 Helsinki, Finland. ${ }^{6}$ Faculty of Social Sciences (Health Sciences), Tampere University, Arvo Ylpön katu 34, 33014 Tampere, Finland. ${ }^{7}$ Finnish Institute of Occupational Health, Aapistie 1, 90220 Oulu, Finland. ${ }^{8}$ Rehabilitation Services of South Karelia Social and Health Care District, Lappeenranta, Finland.

Received: 16 April 2021 Accepted: 19 August 2021

Published online: 07 September 2021

\section{References}

1. GBD 2017 Disease and Injury Incidence and Prevalence Collaborators. Global, regional, and national incidence, prevalence, and years lived with disability for 354 diseases and injuries for 195 countries and territories, 1990-2017: a systematic analysis for the Global Burden of Disease Study 2017. Lancet 2018; 392: 1789-858.

2. Hartvigsen J, Hancock MJ, Kongsted A, Louw Q, Ferreira ML, Genevay S, Hoy D, Karppinen J, Pransky G, Sieper J, Smeets RJ, Underwood M; Lancet Low Back Pain Series Working Group. What low back pain is and why we need to pay attention. Lancet. 2018 Jun 9:391(10137):2356-2367. https:// doi.org/10.1016/S0140-6736(18)30480-X. Epub 2018 Mar 21. PMID: 29573870.

3. Buchbinder R, van Tulder M, Öberg B, Costa LM, Woolf A, Schoene M, Croft P; Lancet Low Back Pain Series Working Group. Low back pain: a call for action. Lancet. 2018 Jun 9;391(10137):2384-2388. https:// doi.org/10.1016/S0140-6736(18)30488-4. Epub 2018 Mar 21. PMID: 29573871.

4. Foster NE, Anema JR, Cherkin D, Chou R, Cohen SP, Gross DP, Ferreira PH, Fritz JM, Koes BW, Peul W, Turner JA, Maher CG; Lancet Low Back Pain Series Working Group. Prevention and treatment of low back pain: evidence, challenges, and promising directions. Lancet. 2018 Jun 9;391(10137):2368-2383. https://doi.org/10.1016/S0140-6736(18)304896. Epub 2018 Mar 21. PMID: 29573872. 
5. Downie A, Hancock M, Jenkins H, Buchbinder R, Harris I, Underwood $M$, Goergen S, Maher CG. How common is imaging for low back pain in primary and emergency care? Systematic review and meta-analysis of over 4 million imaging requests across 21 years. Br J Sports Med. 2020;54(11):642-51. https://doi.org/10.1136/bjsports-2018-100087 Epub 2019 Feb 13 PMID: 30760458.

6. Jenkins HJ, Downie AS, Maher CG, Moloney NA, Magnussen JS, Hancock MJ. Imaging for low back pain: is clinical use consistent with guidelines? A systematic review and meta-analysis. Spine J. 2018;18(12):2266-77. https://doi.org/10.1016/j.spinee.2018.05.004 Epub 2018 May 3 PMID: 29730460.

7. Graves JM, Fulton-Kehoe D, Jarvik JG, Franklin GM. Impact of an Advanced Imaging Utilization Review Program on Downstream Health Care Utilization and Costs for Low Back Pain. Med Care. 2018;56(6):520-8. https://doi.org/10.1097/MLR.0000000000000917 (PMID: 29668650).

8. Jacobs JC, Jarvik JG, Chou R, Boothroyd D, Lo J, Nevedal A, Barnett PG. Observational Study of the Downstream Consequences of Inappropriate MRI of the Lumbar Spine. J Gen Intern Med. 2020. https://doi.org/10. 1007/s11606-020-06181-7. Epub ahead of print. PMID: 32989711.

9. Webster BS, Bauer AZ, Choi Y, Cifuentes M, Pransky GS. latrogenic consequences of early magnetic resonance imaging in acute, work-related, disabling low back pain. Spine (Phila Pa 1976). 2013;38(22):1939-46. https://doi.org/10.1097/BRS.0b013e3182a42eb6. PMID: 23883826; PMCID: PMC4235393.

10. Lily H. Kim, Daniel Vail, Tej D. Azad, Jason P. Bentley, Yi Zhang, Allen L. Ho, Paras Fatemi, Austin Feng, Kunal Varshneya, Manisha Desai, Anand Veeravagu, John K. Ratliff. Expenditures and Health Care Utilization Among Adults With Newly Diagnosed Low Back and Lower Extremity Pain. JAMA Network Open. 2019;2(5):e193676.

11. Owens JD, Hegmann KT, Thiese MS, Phillips AL. Impacts of Adherence to Evidence-Based Medicine Guidelines for the Management of Acute Low Back Pain on Costs of Worker's Compensation Claims. J Occup Environ Med. 2019;61(6):445-52.

12. Hall AM, Scurrey SR, Pike AE, Albury C, Richmond HL, Matthews J, Toomey E, Hayden JA, Etchegary H. Physician-reported barriers to using evidence-based recommendations for low back pain in clinical practice: a systematic review and synthesis of qualitative studies using the Theoretical Domains Framework. Implement Sci. 2019;14(1):49. https://doi.org/10.1186/s13012-019-0884-4. PMID:31064375; PMCID:PMC6505266

13. Sharma S, Traeger AC, Reed B, Hamilton M, O'Connor DA, Hoffmann TC, Bonner C, Buchbinder R, Maher CG. Clinician and patient beliefs about diagnostic imaging for low back pain: a systematic qualitative evidence synthesis. BMJ Open. 2020;10(8): e037820. https://doi.org/10.1136/bmjop en-2020-037820. PMID:32830105; PMCID:PMC7451538.

14. Jenkins HJ, Moloney NA, French SD, Maher CG, Dear BF, Magnussen JS, Hancock MJ. Using behaviour change theory and preliminary testing to develop an implementation intervention to reduce imaging for low back pain. BMC Health Serv Res. 2018;18(1):734. https://doi.org/10.1186/ s12913-018-3526-7. PMID:30249241; PMCID:PMC6154885.

15. Simula AS, Jenkins HJ, Holopainen R, Oura P, Korniloff K, Häkkinen A, Takala EP, Hancock MJ, Karppinen J. Transcultural adaption and preliminary evaluation of "understanding low back pain" patient education booklet. BMC Health Serv Res. 2019;19(1):1010. https://doi.org/10.1186/ s12913-019-4854-y. PMID:31888605; PMCID:PMC6936060.

16. Malmivaara A. Assessing the effectiveness of rehabilitation and optimizing effectiveness in routine clinical work. J Rehabil Med. 2018;50(10):84951. https://doi.org/10.2340/16501977-2495 PMID: 30299525.

17. Rose M, Bjorner JB, Becker J, Fries JF, Ware JE. Evaluation of a preliminary physical function item bank supports the expected advantages of the Patient-Reported Outcomes Measurement Information System (PROMIS). J Clin Epidemiol. 2008;61(1):17-33. https://doi.org/10.1016/j.jclinepi.2006.06. 025.

18. Rose M, Bjorner JB, Gandek B, Bruce B, Fries JF, Ware JE Jr. The PROMIS physical function item bank was calibrated to a standardized metric and shown to improve measurement efficiency. J Clin Epidemiol. 2014;67(5):516-26. https://doi.org/10.1016/j.jclinepi.2013.10.024.

19. Fairbank JC, Pynsent PB. The Oswestry Index. Spine (Phila Pa 1976) 2000;25(22):2940-52

20. Rabin R, Gudex C, Selai C, Herdman M. From translation to version management: a history and review of methods for the cultural adaptation of the EuroQol five-dimensional questionnaire. Value Health. 2014;17(1):706. https://doi.org/10.1016/j.jval.2013.10.006.

21. Ribeiro DC, Milosavljevic S, Abbott JH. Sample size estimation for cluster randomized controlled trials. Musculoskelet Sci Pract. 2018;34:108-11. https://doi.org/10.1016/j.msksp.2017.10.002 Epub 2017 Oct 12 PMID: 29037472.

22. Hays RD, Spritzer KL, Fries JF, Krishnan E. Responsiveness and minimally important difference for the patient-reported outcomes measurement information system (PROMIS) 20-item physical functioning short form in a prospective observational study of rheumatoid arthritis. Ann Rheum Dis. 2015;74(1):104-7. https://doi.org/10.1136/ annrheumdis-2013-204053. Epub 2013 Oct 4. PMID: 24095937; PMCID: PMC3976454.

23. Lane E, Fritz JM, Greene T, Maddox D. The effectiveness of training physical therapists in pain neuroscience education on patient reported outcomes for patients with chronic spinal pain: a study protocol for a cluster randomized controlled trial. BMC Musculoskelet Disord. 2018;19(1):386. https://doi.org/10.1186/s12891-018-2269-2. PMID:30360762; PMCID:PMC6203285.

24. Dagenais S, Galloway EK, Roffey DM. A systematic review of diagnostic imaging use for low back pain in the United States. Spine J. 2014;14(6):1036-48. https://doi.org/10.1016/j.spinee.2013.10.031 Epub 2013 Nov 8 PMID: 24216398.

25. Fried JG, Andrew AS, Ring NY, Pastel DA. Changes in Primary Care Health Care Utilization after Inclusion of Epidemiologic Data in Lumbar Spine MR Imaging Reports for Uncomplicated Low Back Pain. Radiology. 2018;287(2):563-9. https://doi.org/10.1148/radiol.2017170722 Epub 2018 Jan 22 PMID: 29361247.

26. McCullough BJ, Johnson GR, Martin BI, Jarvik JG. Lumbar MR imaging and reporting epidemiology: do epidemiologic data in reports affect clinical management? Radiology. 2012;262(3):941-6. https://doi.org/10.1148/ radiol.11110618. PMID:22357893; PMCID:PMC3285226.

27. Jarvik JG, Meier EN, James KT, Gold LS, Tan KW, Kessler LG, Suri P, Kallmes DF, Cherkin DC, Deyo RA, Sherman KJ, Halabi SS, Comstock BA, Luetmer $\mathrm{PH}$, Avins AL, Rundell SD, Griffith B, Friedly JL, Lavallee DC, Stephens KA, Turner JA, Bresnahan BW, Heagerty PJ. The Effect of Including Benchmark Prevalence Data of Common Imaging Findings in Spine Image Reports on Health Care Utilization Among Adults Undergoing Spine Imaging: A Stepped-Wedge Randomized Clinical Trial. JAMA Netw Open. 2020;3(9): e2015713. https://doi.org/10.1001/jamanetworkopen.2020.15713. PMID:32886121; PMCID:PMC7489827.

28. Ree E, Lie SA, Eriksen HR, Malterud K, Indahl A, Samdal O, Harris A Reduction in sick leave by a workplace educational low back pain intervention: A cluster randomized controlled trial. Scand J Public Health. 2016;44(6):571-9. https://doi.org/10.1177/1403494816653854. Epub 2016 Jun 15. PMID: 27307465; PMCID: PMC4941097.

29. Rantonen J, Karppinen J, Vehtari A, Luoto S, Viikari-Juntura E, Hupli M, Malmivaara A, Taimela S. Cost-effectiveness of providing patients with information on managing mild low-back symptoms in an occupational health setting. BMC Public Health. 2016;12(16):316. https://doi.org/10.1186/s12889-016-2974-4. PMID:27068751; PMCID:PMC4828818.

30. Lemmers GPG, van Lankveld W, Westert GP, van der Wees PJ, Staal JB. Imaging versus no imaging for low back pain: a systematic review, measuring costs, healthcare utilization and absence from work. Eur Spine J. 2019;28(5):937-50. https://doi.org/10.1007/s00586-019-05918-1 Epub 2019 Feb 22 PMID: 30796513.

31. Powell AC, Rogstad TL, Elliott SW, Price SE, Long JW, Deshmukh UU, Murad MH, Steffen MW. Health Care Utilization and Pain Outcomes Following Early Imaging for Low Back Pain in Older Adults. J Am Board Fam Med. 2019;32(6):773-780. https://doi.org/10.3122/jabfm.2019.06.190103. PMID: 31704745

32. Traeger AC, Hübscher M, Henschke N, Moseley GL, Lee H, McAuley JH. Effect of Primary Care-Based Education on Reassurance in Patients With Acute Low Back Pain: Systematic Review and Meta-analysis. JAMA Intern Med. 2015;175(5):733-43. https://doi.org/10.1001/jamainternmed.2015. 0217 PMID: 25799308.

33. Lorenzo A, Schildt P, Lorenzo M, Falcoff H, Noel F. Acute low back pain management in primary care: a simulated patient approach. Fam Pract. 2015;32(4):436-41. https://doi.org/10.1093/fampra/cmv030 Epub 2015 Jun 8 PMID: 26060210. 
34. Jenkins HJ, Hancock MJ, French SD, Maher CG, Engel RM, Magnussen JS. Effectiveness of interventions designed to reduce the use of imaging for low-back pain: a systematic review. CMAJ. 2015;187(6):401-8.

35. Slade SCP, Kent PP, Patel SDP, Bucknall TP, Buchbinder RP. Barriers to primary care clinician adherence to clinical guidelines for the Management of low Back Pain: a systematic review and meta-synthesis of qualitative studies. Clin J Pain. 2016;32(9):800-16.

\section{Publisher's Note}

Springer Nature remains neutral with regard to jurisdictional claims in published maps and institutional affiliations.

- fast, convenient online submission

- thorough peer review by experienced researchers in your field

- rapid publication on acceptance

- support for research data, including large and complex data types

- gold Open Access which fosters wider collaboration and increased citations

- maximum visibility for your research: over $100 \mathrm{M}$ website views per year

At BMC, research is always in progress.

Learn more biomedcentral.com/submissions 